\title{
Gilles Teissonnières, La Tour Eiffel. Une ethnologie d'un espace touristique
}

Coll. "Le regard de l'ethnologue", éditions CTHS, 2011, 367 pages

\section{Christophe Guibert}

\section{OpenEdition}

\section{Journals}

Édition électronique

URL : http://journals.openedition.org/tourisme/210

DOI : 10.4000/tourisme.210

ISSN : 2492-7503

Éditeur

Éditions touristiques européennes

\section{Édition imprimée}

Date de publication : 1 juin 2013

Pagination : 111-112

ISSN : 2109-5671

\section{Référence électronique}

Christophe Guibert, «Gilles Teissonnières, La Tour Eiffel. Une ethnologie d'un espace touristique », Mondes du Tourisme [En ligne], 7| 2013, mis en ligne le 30 septembre 2015, consulté le 22 septembre 2020. URL : http://journals.openedition.org/tourisme/210 ; DOI : https://doi.org/10.4000/tourisme. 210

Ce document a été généré automatiquement le 22 septembre 2020

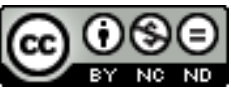

Mondes du tourisme est mis à disposition selon les termes de la licence Creative Commons Attribution - Pas d'Utilisation Commerciale - Pas de Modification 4.0 International. 


\title{
Gilles Teissonnières, La Tour Eiffel. Une ethnologie d'un espace touristique
}

\author{
Coll. “Le regard de l'ethnologue", éditions CTHS, 2011, 367 pages
}

\section{Christophe Guibert}

\section{RÉFÉRENCE}

Gilles Teissonnières, La Tour Eiffel. Une ethnologie d'un espace touristique, coll. "Le regard de l'ethnologue", éditions CTHS, 2011.

1 Cet ouvrage traite d'un lieu singulier à l'aune d'analyses et d'interprétations ethnologiques. Pour l'auteur, qui justifie son terrain, "le site touristique de la tour Eiffel occupe une place spécifique dans l'univers urbain et patrimonial"; c'est "un lieu propice à une ethnographie des pratiques touristiques" (p. 347). Convoquant Claude Lévy-Strauss, Gilles Teissonnières envisage de traiter son objet "totalement".

$2 \mathrm{Si}$, comme son nom l'indique, l'ancrage disciplinaire de l'auteur est l'ethnologie, force est de constater que, comme c'est l'usage dans cette discipline, les matériaux empiriques variés sont largement exposés et confèrent à la lecture beaucoup de plaisir. Des illustrations et cartes postales anciennes, des cartes, des schémas, de nombreuses photographies (de l'auteur ou non) et des extraits de carnets de terrain avec des extraits d'entretiens (des "notes de terrain") à profusion (datés et contextualisés) permettent à Gilles Teissonnières de confirmer ses hypothèses de recherche, chaque matériau agissant tel un élément pertinent de preuve.

Quatre parties composent cet ouvrage de 267 pages. La première, "Un monument, des visiteurs, une ville", plante le décor en mobilisant des données historiques, quantitatives et typologiques (transformations du processus de symbolisation de la tour Eiffel, fréquentations touristiques, modalités touristiques du lieu, etc.). Pour l'auteur, la tour Eiffel, avec plus de 200 millions de visiteurs (en cumulé depuis son inauguration en 1889), reconnaissable par tous dans le monde, est à la fois un lieu de 
commémoration et un "monument sacré", voire un symbole sexuel (l'auteur s'inspirant ici de visions littéraires d'Aragon ou de Barthes). Ces représentations varient également, d'après l'auteur, selon le type de visiteur (touriste étranger ou non, provincial visitant Paris, etc.), impliquant potentiellement des effets de coprésence. Aussi, à l'image de Paris, "la tour Eiffel constitue un espace cosmopolite dense" (p. 41).

La seconde partie, "Des territorialités superposées", analyse cet espace touristique sous l'angle des valorisations marchandes et composites (la société d'exploitation, les commerces aux alentours, les vendeurs à la sauvette, etc.) mais aussi des modalités différenciées de l'usage de l'espace dans et autour la tour Eiffel par les touristes. Le quartier qui environne la tour Eiffel est un "espace multidimensionnel et très contrasté" (p.103). Une analyse des tenues vestimentaires et des représentations spontanées qu'elles engendrent, des modalités d'utilisation des guides touristiques ou encore des types de vendeurs (légaux ou illégaux...) renforce la thèse de l'auteur dans ce chapitre.

5 La troisième partie, intitulée "Sur la tour Eiffel", analyse finement les usages variés, par les touristes, de l'édifice pris pour objet. Les modalités d'appropriation du lieu, les sens conférés, les "étapes matérielles qu'il convient de franchir successivement" (p. 227) ou encore les usages de la restauration par les touristes constituent ici un panorama coloré des manières de visiter. Du pied de la tour au troisième et dernier étage, Gilles Teissonnières étudie les comportements tels que la façon dont s'organise la queue liée à l'attente, les déambulations des visiteurs, les "usages décalés", les manières de s'approprier l'espace en prenant des photos ou en gravant des messages personnels avec des graffitis, etc. L'auteur s'attarde par ailleurs sur les usages et modalités de consommation au sein des multiples établissements de restauration: restauration rapide brandissant l'argument de la "tradition" (p. 264); restaurants plus élitistes, comme l'Altitude 95 et sa "cuisine classique de brasserie" (p. 274) et, surtout, le Jules Verne dont le fait d'y déjeuner ou d'y dîner "constitue une démarche en elle-même" (p. 278).

6 Enfin, "Un espace hétérogène", le quatrième et dernier chapitre, met en lumière les "paradoxes" de ce haut lieu touristique. Gilles Teissonnières met en évidence les visions contradictoires et binaires que peut inspirer la tour Eiffel: des économies institutionnalisées et des économies informelles, un monument culturel ou une attraction, des "riches" et des "pauvres"... Si "le territoire de la tour Eiffel apparaît comme un espace mobilisé à des fins commerciales" (p. 298), telle une "machine à produire du cash", cette logique est, archives à l'appui, déjà repérée dès le début du $\mathrm{xx}^{\mathrm{e}}$ siècle. La diversification des pratiques commerciales est dorénavant une constante, allant du commerce "officiel" dans les étages de la tour, aux commerces sur les boulevards adjacents, en passant par les vendeurs à la sauvette. Cette variabilité caractérise également, selon l'auteur, les touristes eux-mêmes, des plus modestes à ceux fortement dotés en capitaux économiques. Il en résulte un rapport éminemment social à l'espace physique de la tour Eiffel en ce qui concerne les consommations dans les boutiques de souvenirs et, particulièrement, des restaurants. Les étages et différents espaces de la tour Eiffel agissent tels des marqueurs sociaux structurants (p.315): "Cette hiérarchisation spatiale des espaces de vente restitue l'image d'une hiérarchisation sociale" (p. 320).

7 Si le contrat croisement théorie/terrain est tout à fait cohérent eu égard à la richesse des matériaux et aux références théoriques convoqués (ethnologie, mais aussi géographie, sociologie, histoire), la thèse générale de l'ouvrage, autrement dit le point 
où l'auteur veut "emmener" le lecteur, n'est toutefois pas clairement établie. Chaque partie de l'ouvrage peut d'ailleurs se lire indépendamment des autres, laissant transparaître l'idée d'une addition de thèmes. Malgré la précision descriptive des matériaux (en particulier des "notes de terrain"), il est difficile de savoir réellement qui sont ces visiteurs, ces touristes de la tour Eiffel. La difficulté provient sans doute du terrain lui-même - et de la volonté de l'auteur de le traiter "totalement" - : l'hétérogénéité des propriétés sociales des individus, la grande variété des usages (sociaux et spatiaux) du site et l'aspect hors norme de ce dernier sur le plan de la fréquentation rendent l'entreprise ardue, mécaniquement.

\section{AUTEURS}

\section{CHRISTOPHE GUIBERT}

Université d'Angers 